Vol.5 (3); 2015,65-78 ميزان انطباق برنامهُ درسى قصد شده و اجرا شدهُ ييش از دبستان

\title{
A Study of correspondence between Intended and Implemented Curricula of pre- primary school
}

\section{A. Razavi (Ph.D.) ,Kh. Gorji Poshti}

Abstract The goal of current study was to investigate the consistency of intended curriculum with implemented curriculum at the preprimary level. The research method was survey study. The population included 258 preschool teachers of west of Mazandaran in 2009 that 122 samples randomly selected from Abas Abad, Chaloose, Tonekabon and Ramsar cities. Measuring tool was researcher-made questionnaire consists of 29 statements with Likert five points Scale. This questionnaire measured the implemented curriculum from the aspects of goals, activities and methods in evaluation. Face validity of the questionnaire has been investigated through the current issues in curriculum plan and educational activities of preschool and 2 professors been confirmed. The reliability of the questionnaire was found 0/91. Analyzing the data has been done by using descriptive statistics (mean, standard deviation and column diagram drawing) and inferential statistics (paired T test). Results showed that from the point of view of preschool centers' teachers, there was a somehow conformity among goals, activities and evaluating methods in intended curriculum with implemented curriculum. Comparative investigation among respondents'ideas in getting the goals showed that most amount of reching goals was related to cognitive aspect with average point of $21 / 39$ and the least amount of getting the goals was related to emotional aspect with average point of $8 / 22$. Also in implemented activities, poems and signing, drawing, storytelling, group discussion and playing respectively are the most done activities by teachers. About how to evaluate by teachers in implemented curriculum, observation (\%46), oral evaluation (\%45) and continuous evaluation (\%36) were the most applied methods.

Key Words: Intended curriculum, Implemented curriculum, Preschool level.

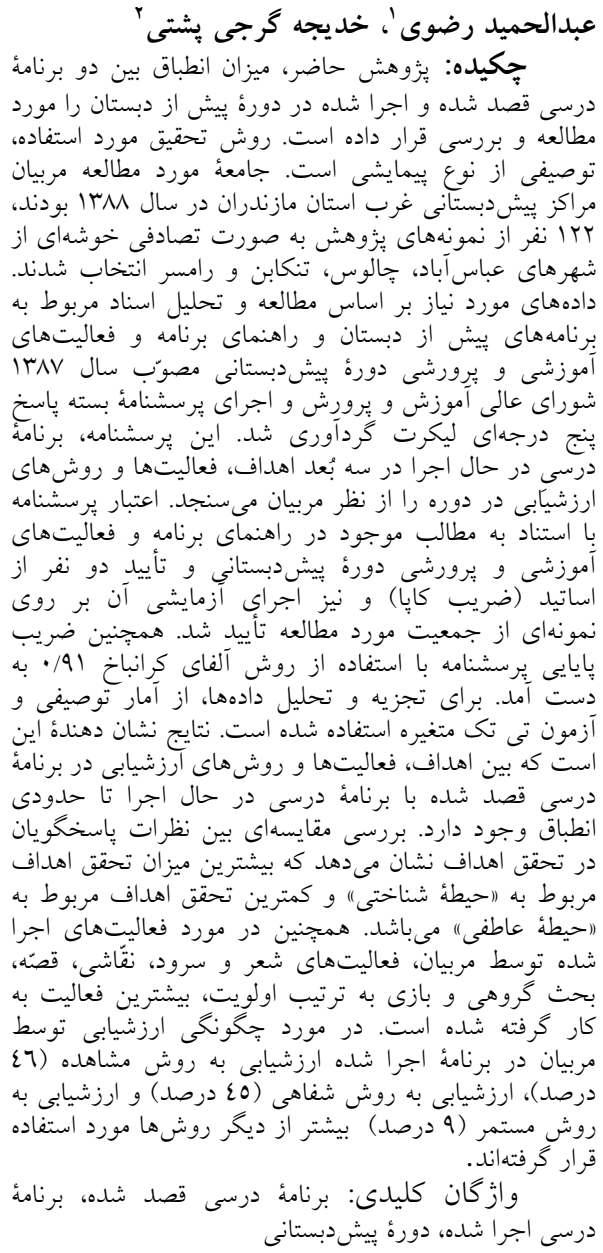

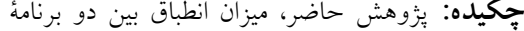

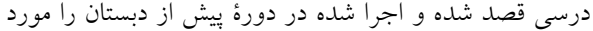

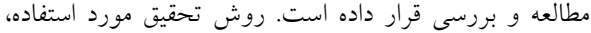

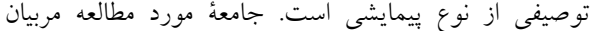

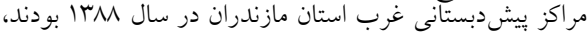

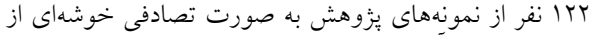

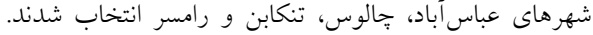

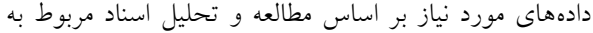

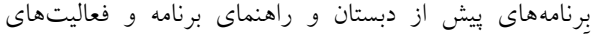

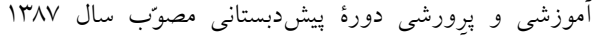

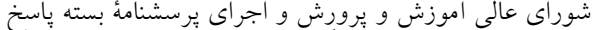

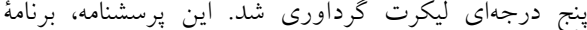

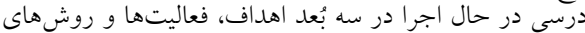

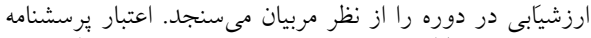

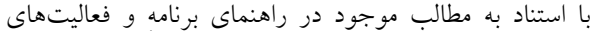

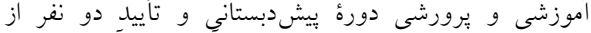

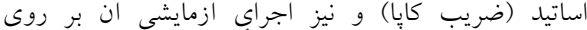

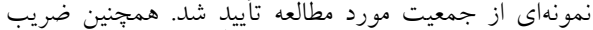

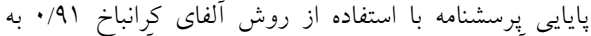

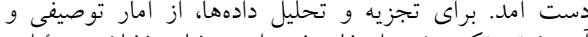

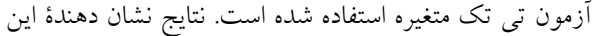

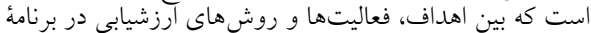

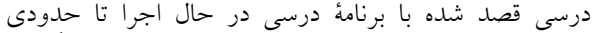

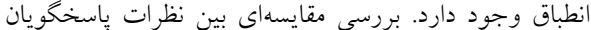

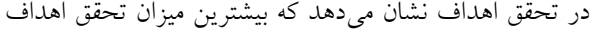

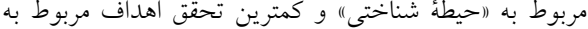

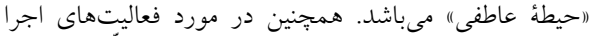

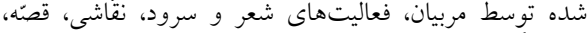

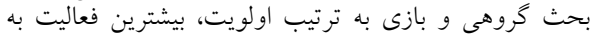

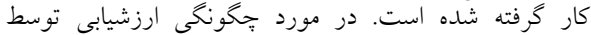

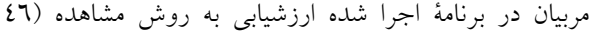

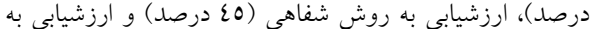

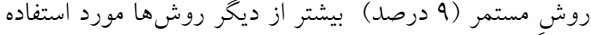

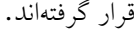

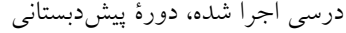

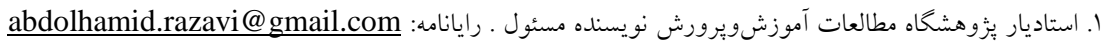

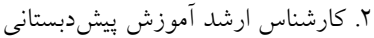

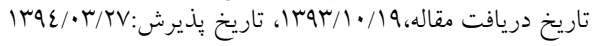




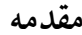

برنامهٔ درسى شامل فرصتهاى يادكيرى و كليئ تجاربى است كه با نظارت و مسئوليت

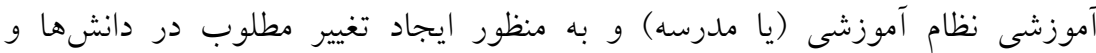

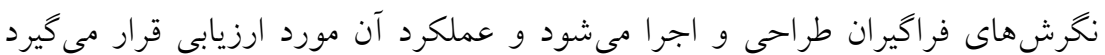

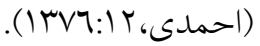

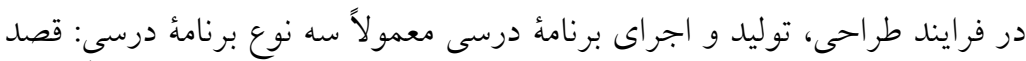

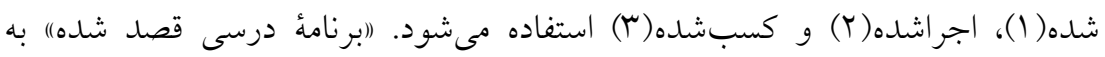

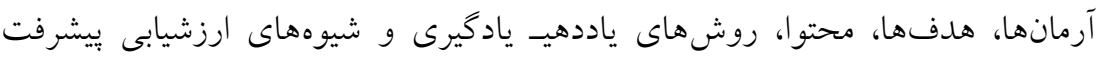

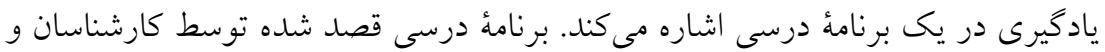

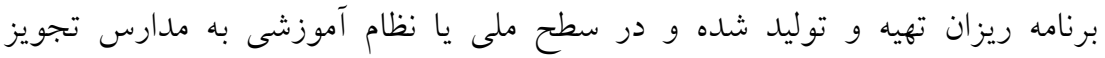

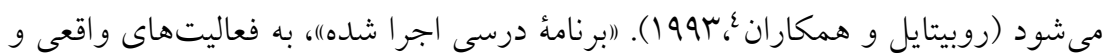

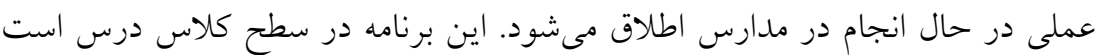

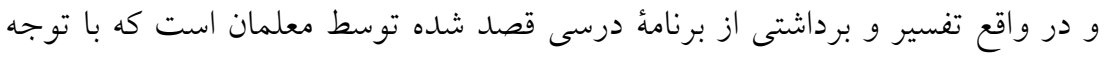

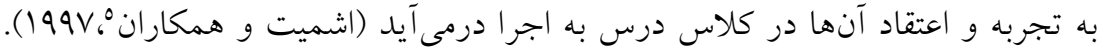

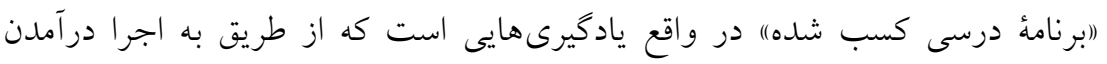

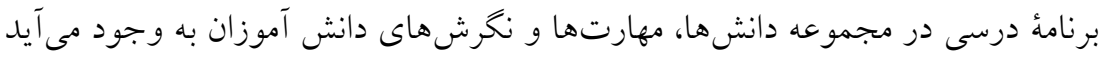

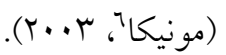

در نظام آموزشى ايران يكى از دورههاى آموزشى كه طى سالهاى مختلف كاه به

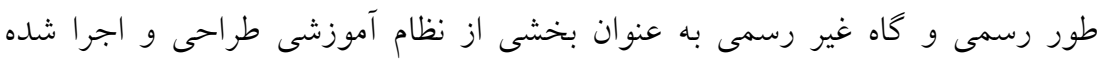

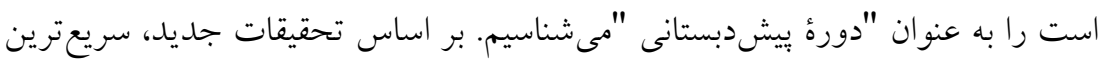

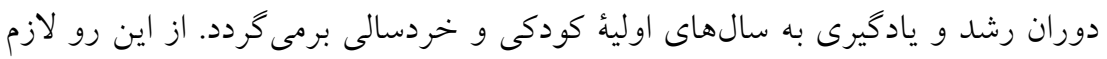

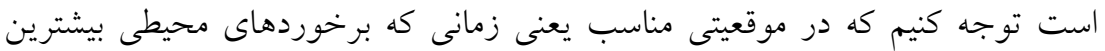

1 -Intended curriculum

2 -Implemented curriculum

3 -Attained curriculum

4 -Robitaille. D.F.et al

5 -Schmidt, M.H. et al

6 - Monica,J 
تأثير را در شكوفايى استعدادهاى ذاتى كودى مى گذارد، به كار آموزش و تربيت اهتمام

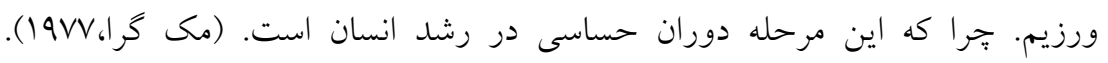

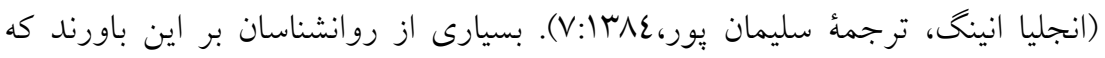

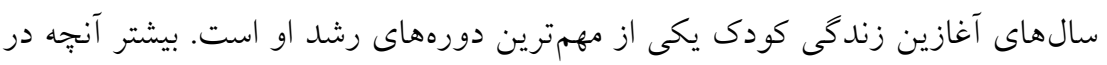

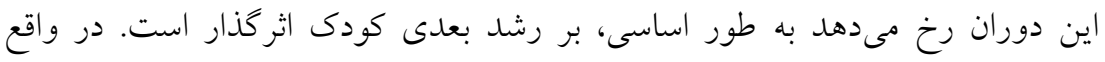

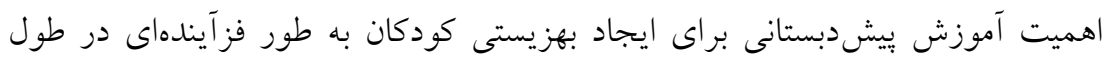

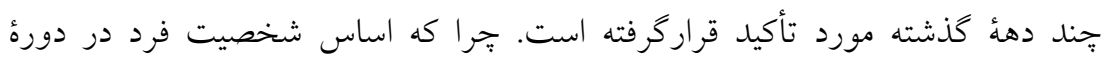

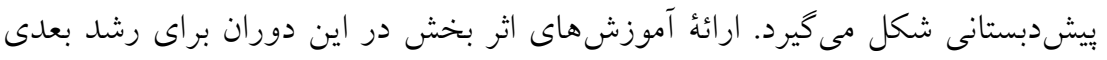

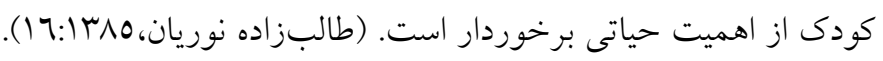

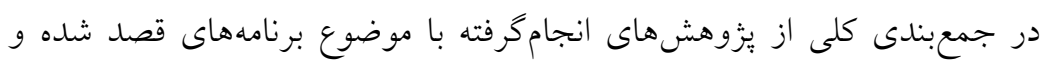

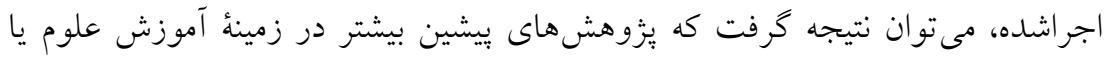

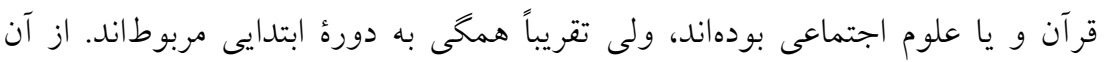

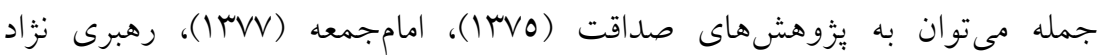

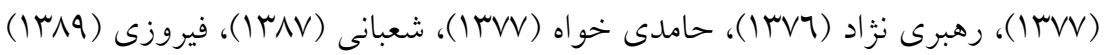

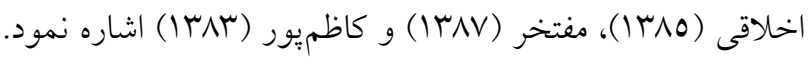

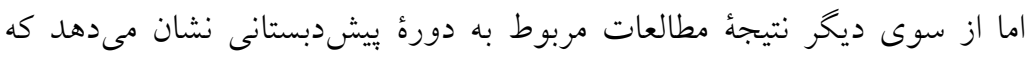

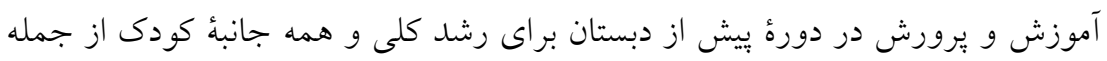

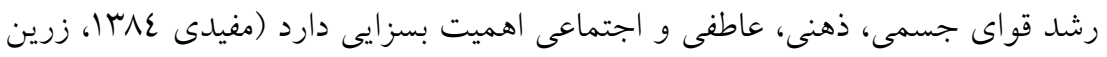

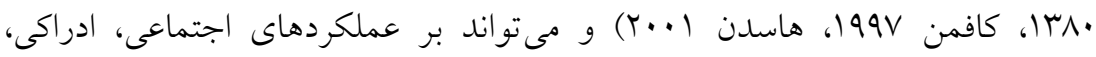

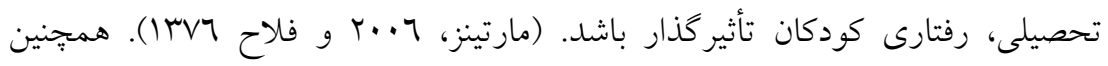

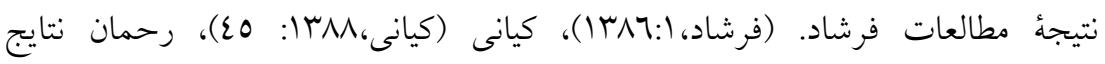

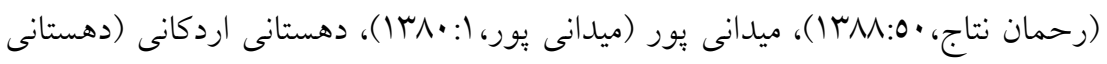

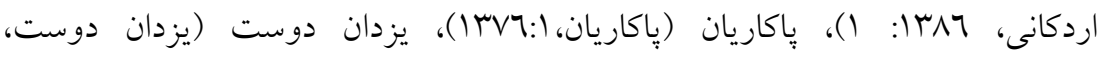
1Y)

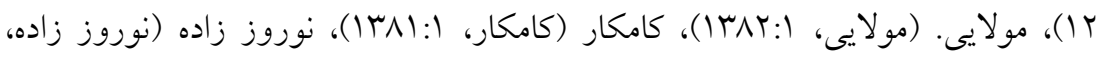
r

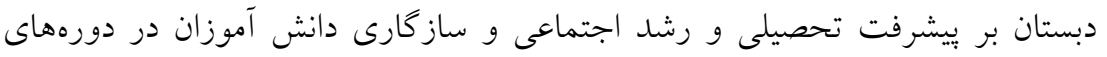
بعدى زندگى و به ويزه در دورة ابتدايى تأكيد دارند. 
به لحاظ جنين اثرات مهمى امروزه آموزش و يُرورش در دوره يِيش از دبستان،

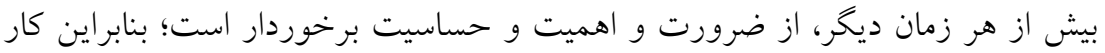

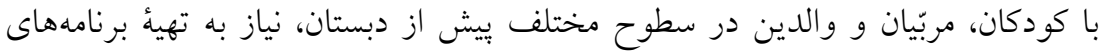

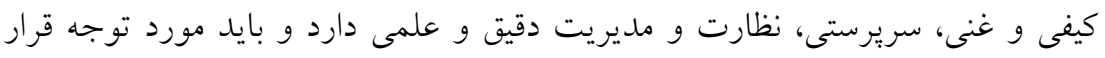

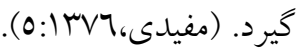

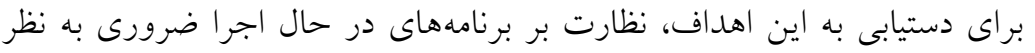

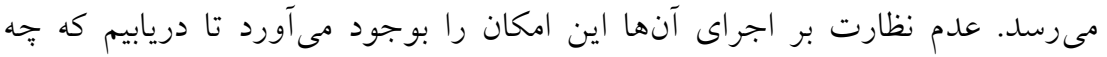
اندازه ميان برنامه قصد شده و اجرا شده در سه محور اصلى برنامه، يعنى هدفهائا

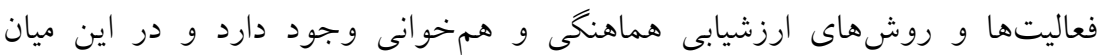

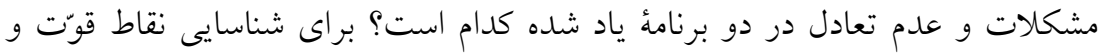

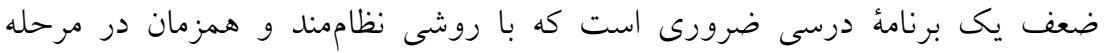

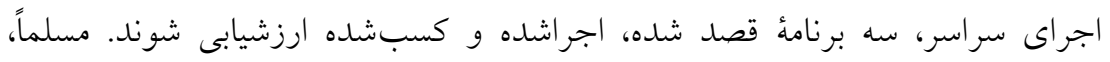

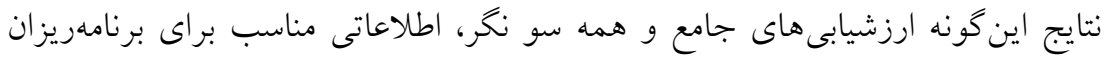

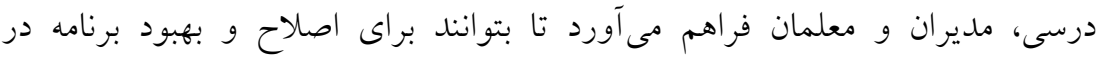

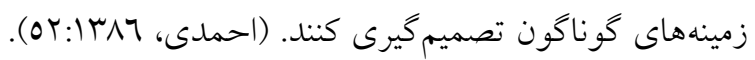

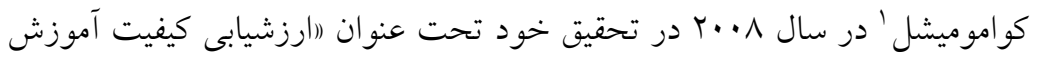

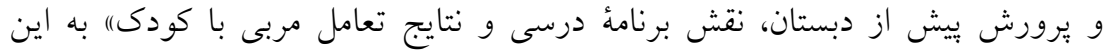

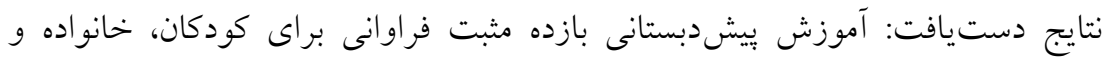

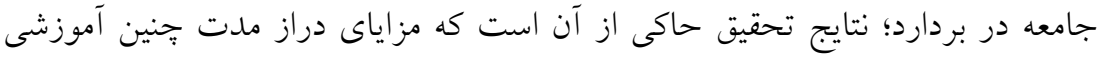

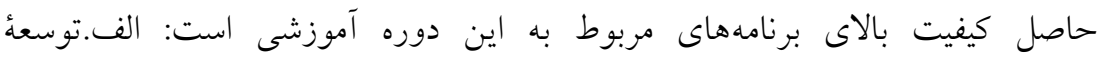

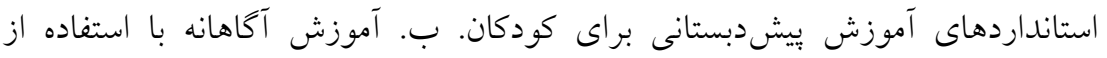

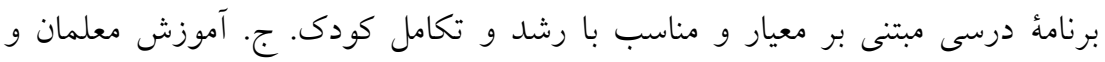

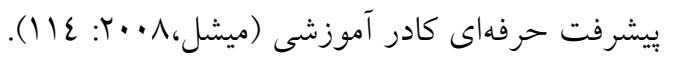

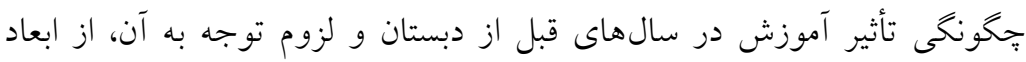

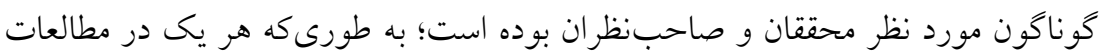

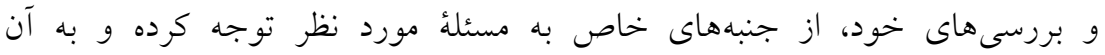


برداختهاند، با توجه به تأثير آموزشهاى قبل از دبستان در ابعاد كوناكون رشد، اين

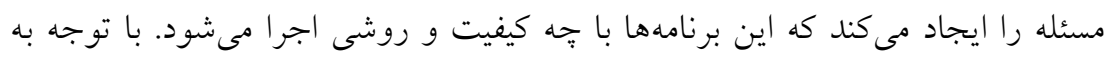

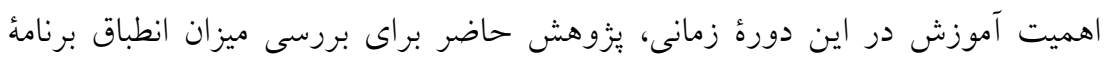

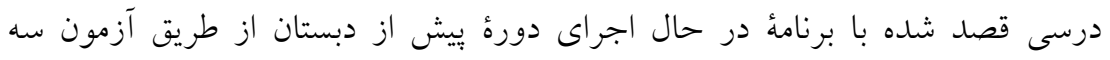
فرضئ زير انجامخرفته است:

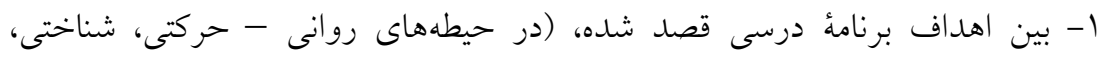

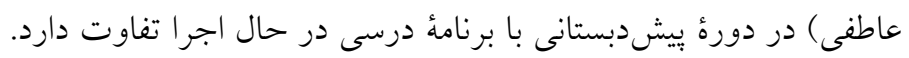

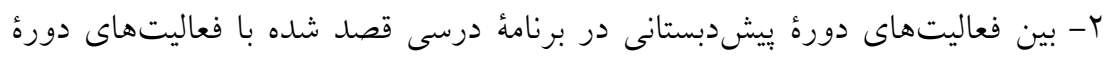

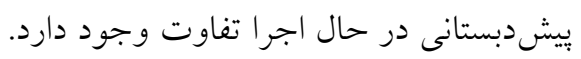

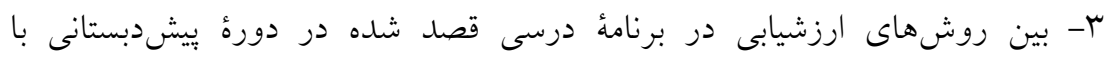

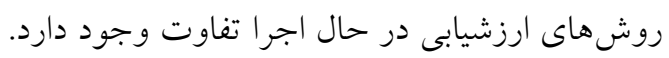

\section{روش شناسى بيزوهش}

مطالعهُ حاضر با توجه به ماهيت، هدف و وسؤالات تحقيق به روش توصيفى' و از نوع بيمايشى ب انجام كرفت.

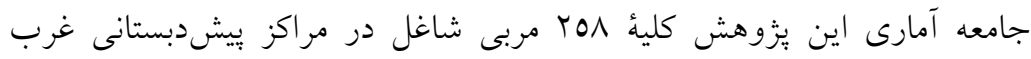

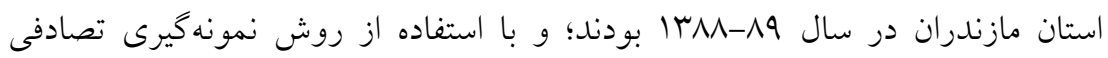

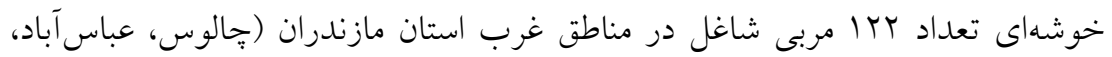

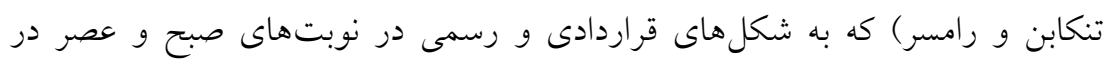

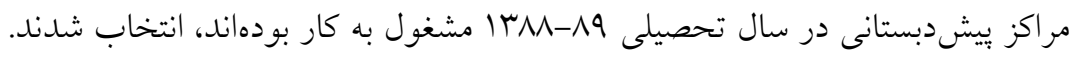

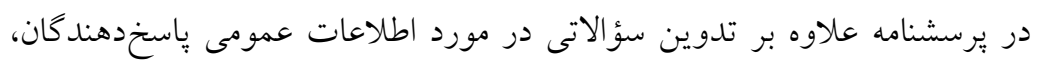

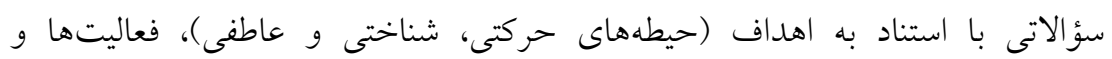

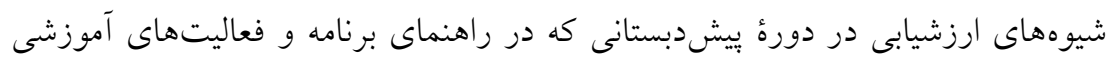

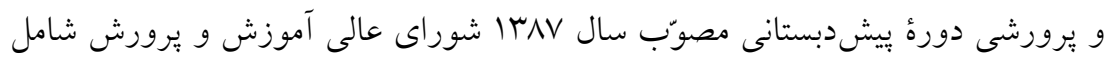

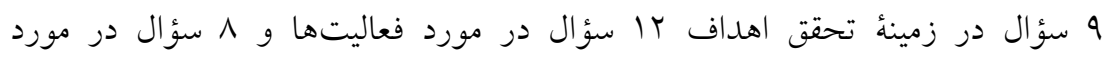
شيوههاى ارزشيابى اين دوره طراحى شد.

1- Discriptive

2- Survey 
روايى محتو ايى ابزار با استفاده از نظر دو نفر از كارشناسان ارشد يِشدبستانى و دو نفر

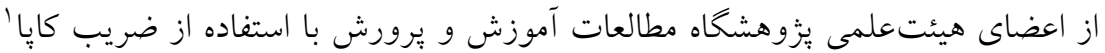

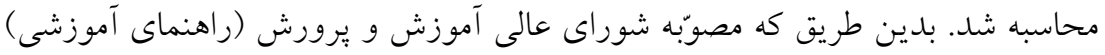

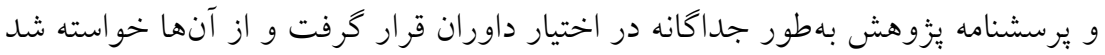

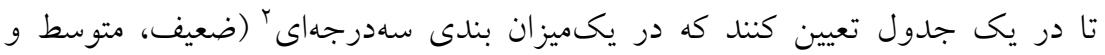

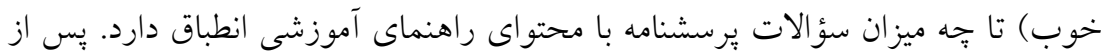

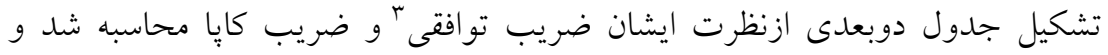
معنى مار بود (جدول (1).

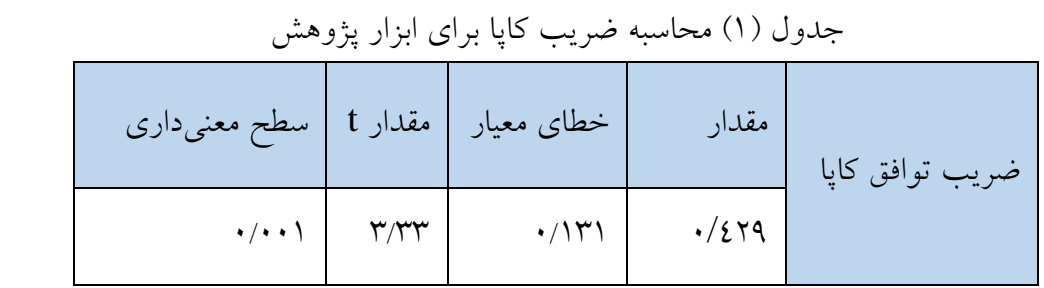
براى محاسبة هِايايى از آلفاى كرونباخ استفاده شد. ضريب يايايى بهدستآمده

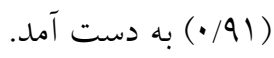

براى اطمينان از آكاهى مربيان از محتواى برنامه قصد شده دورةٌ بيشدبستانى،

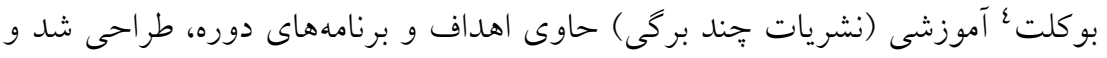

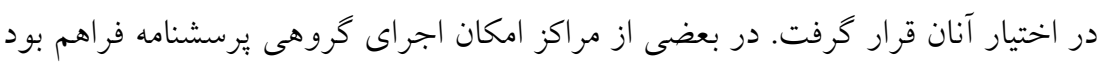

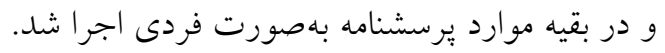

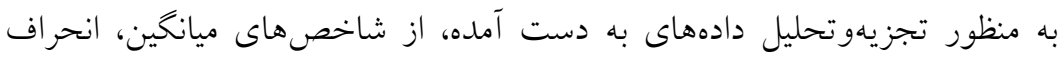

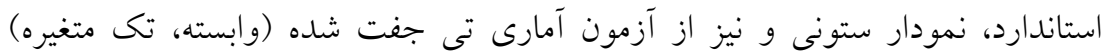

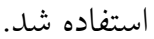

1.Cohen's kappa

2 .scale

3 .Crosstabs' ordinal-by-ordinal measures

4. Booklet 


\section{يافتهاى تحقيق \\ فرضيه اول:}

بين اهداف برنامهٔ درسى قصد شده (در حيطههاى روانى حركتى، شناختى، عاطفى)

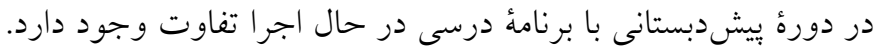

جدول (Y): مقايسه اهداف كلى برنامه قصد شده و اجراشده

\begin{tabular}{|c|c|c|c|c|c|c|}
\hline سطنادارى & آزادى درجه & مشاهدهشده & بحرانى & انحتاف انداف & ميانگين & \\
\hline \multirow[t]{2}{*}{$\cdot 1 \cdots$} & \multirow[t]{2}{*}{$|r|$} & \multirow[t]{2}{*}{$11 / 7}$. & \multirow[t]{2}{*}{ r/OVT } & 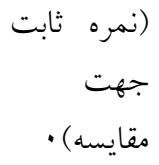 & TV & قصد شدامه \\
\hline & & & & $1 \cdot / \varepsilon \varepsilon$ & rV/aTVT & برنامه اشده \\
\hline
\end{tabular}

همان كونه كه در جدول (Y) ديده مى شود ميانكين ارزشيابى از اهداف كلى در برنامه

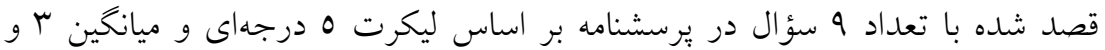

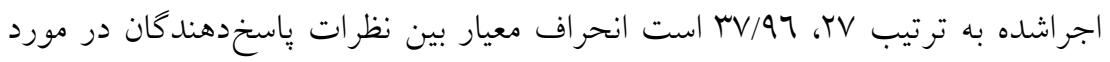

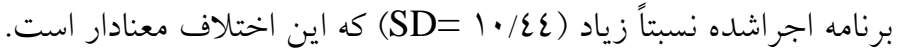

جدول (r) مقايسه اهداف روانى حركتى برنامهٔ درسى قصد شده و اجراشده

\begin{tabular}{|c|c|c|c|c|c|c|}
\hline سعنادارى & درآز درجه & مشاهدهشده & t بحر انى & انحتاف اندارد & ميانخين & \\
\hline \multirow[t]{2}{*}{$\bullet$} & \multirow[t]{2}{*}{$|r|$} & \multirow[t]{2}{*}{$19 / 7 \vee 7$} & \multirow[t]{2}{*}{ Y/OVT } & 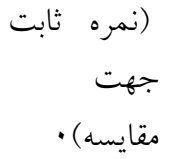 & 7 & قصد شامه \\
\hline & & & & $\mid / / 1$ & $\Lambda / \Upsilon \varepsilon$ & برنامه اشده \\
\hline
\end{tabular}




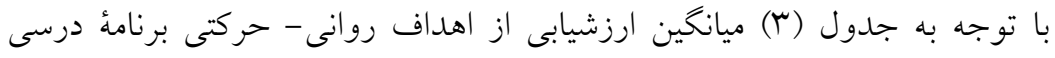

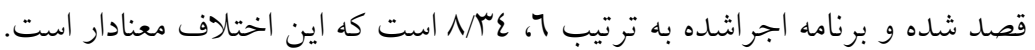

جدول (ع): مقايسه اهداف شناختى قصد شده و اجراشده

\begin{tabular}{|c|c|c|c|c|c|c|}
\hline سعادارى & دآزادى & مشاهدهشه & أبحر انى & انحتافداف النارد & ميانخين & \\
\hline \multirow[t]{2}{*}{$\cdot / \cdots$} & \multirow[t]{2}{*}{$|r|$} & \multirow[t]{2}{*}{$V / T Y V$} & \multirow[t]{2}{*}{ r/OVT } & 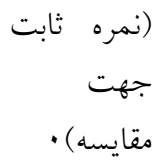 & 10 & قصد شدامه \\
\hline & & & & Q/VV & $r 1 / r q$ & برنامه اشده \\
\hline
\end{tabular}

همانطورى كه در جدول (ع) ديده مىشود ميانخين ارزشيابى از اهداف شناختى

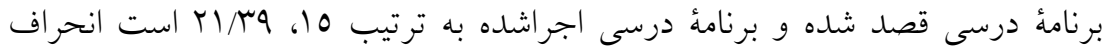

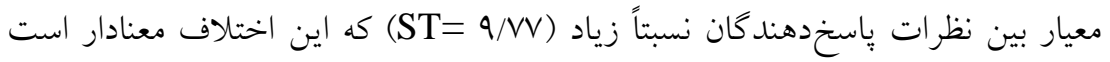

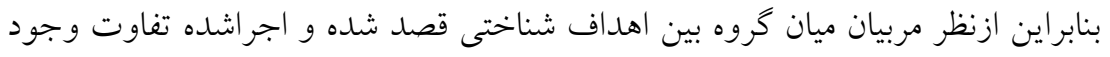
دارد.

جدول (0): مقايسه اهداف عاطفى برنامةٔ درسى قصد شده و اجراشده

\begin{tabular}{|c|c|c|c|c|c|c|}
\hline سعنادارى & درجه & t & بحرانى t بح & استحر اف افندارد & ميانكين & \\
\hline \multirow[t]{2}{*}{$\cdot / \cdots$} & \multirow[t]{2}{*}{$|r|$} & \multirow[t]{2}{*}{$1 V / 0.1$} & \multirow[t]{2}{*}{ r/OVT } & (نمره & 7 & قصد شده \\
\hline & & & & $1 / \varepsilon \cdot V$ & $N / T Y$ & برامرامه \\
\hline
\end{tabular}

با توجه به جدول (0) ميانخين ارزشيابى از اهداف عاطفى برنامهُ درسى قصد شده

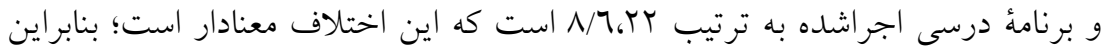

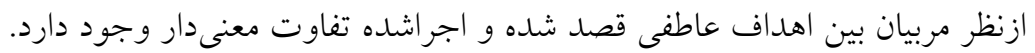




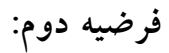

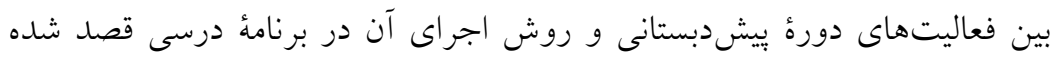

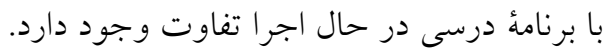

جدول (7): مقايسه تفاوت فعاليتهاى قصد شده و اجر اشده

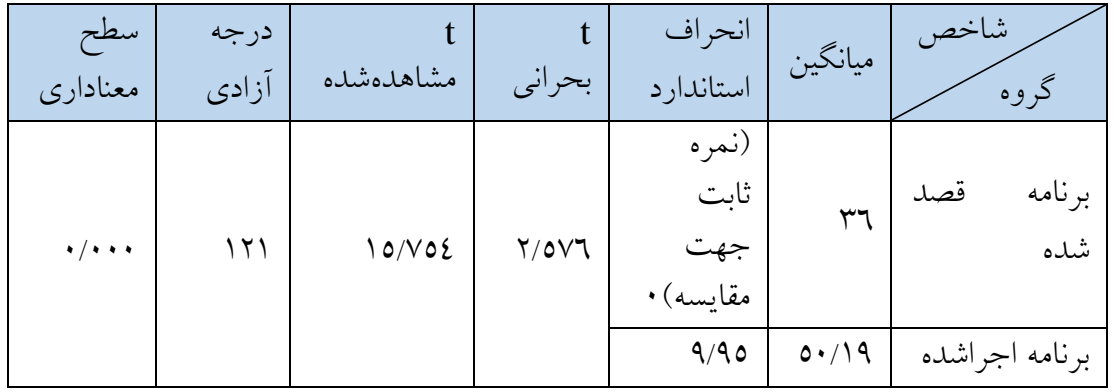

با توجه به جدول (7) ميانخين ارزشيابى از فعاليتهاى برنامهٔ درسى قصد شده و

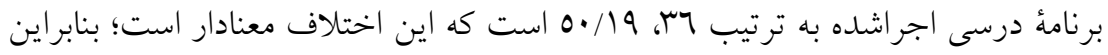
بين فعاليتهاى قصد شده و اجر اشده تفاوت معنى دار وجود بـد دارده

\section{فرضيه سوم:}

بين روشهاى ارزشيابى برنامة درسى قصد شده در دورة بيشدبستانى با روشها

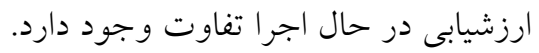

جدول (V): مقايسه تفاوت روشهاى ارزشيابى برنامةٔ درسى قصد شده و اجراشده

\begin{tabular}{|c|c|c|c|c|c|c|}
\hline سعنادارى & درجه & مشاهدهده & أبحر انى & انحراف استاندارد & ميانخين & \\
\hline \multirow{2}{*}{$\cdot / \cdots$} & \multirow{2}{*}{$|r|$} & \multirow{2}{*}{$10 / 1 \Lambda}$. & \multirow{2}{*}{ r/OV7 } & 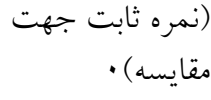 & $r \varepsilon$ & شرنامه قصد \\
\hline & & & & $\varepsilon / 77$ & $r \cdot / \varepsilon$. & اجراشده \\
\hline
\end{tabular}

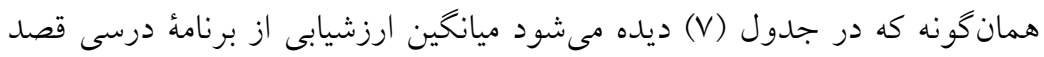

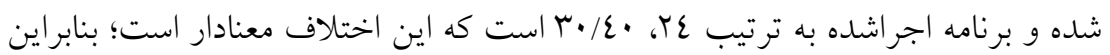


ازنظر مربيان بين روشهاى ارزشيابى در برنامهُ درسى قصد شده و برنامه اجراشده تفاوت معنى دار وجود دارد.

\section{بحث و نتيجه گيرى}

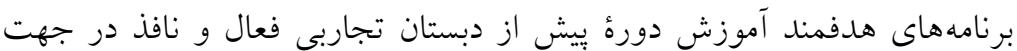

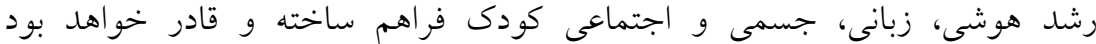

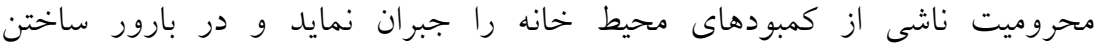

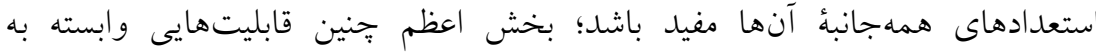

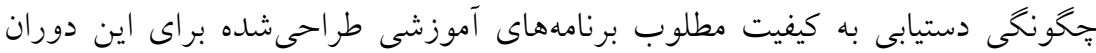

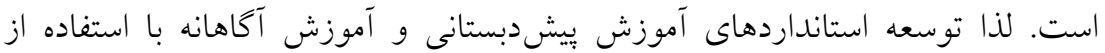

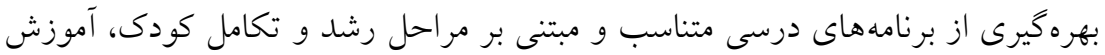

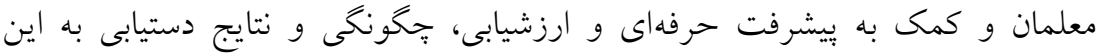

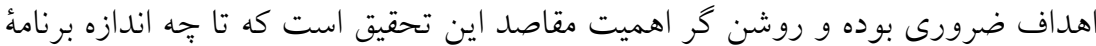

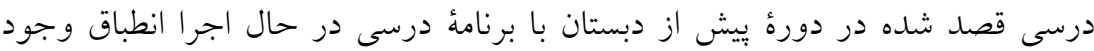
دارد.

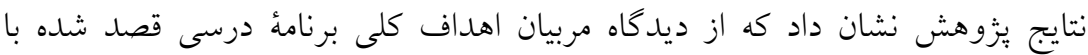

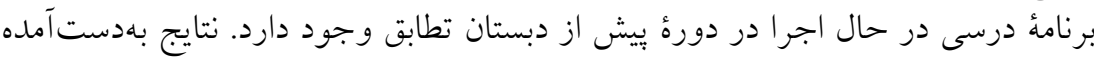

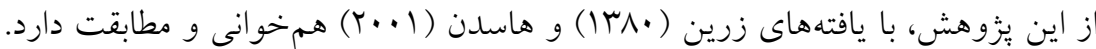

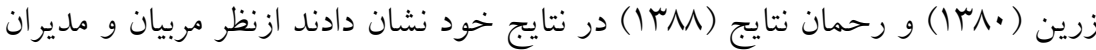

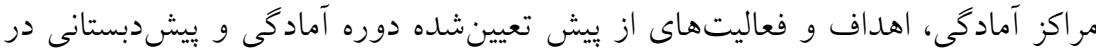

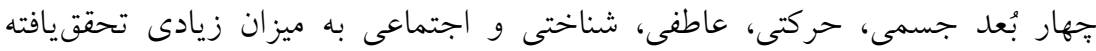

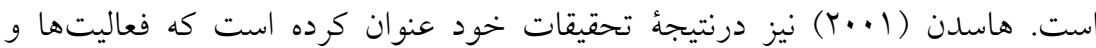

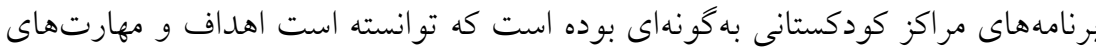

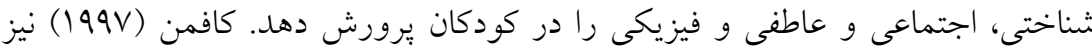

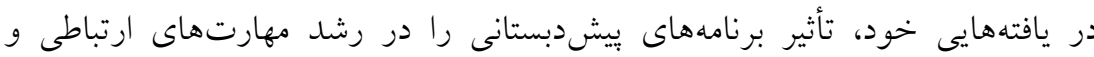

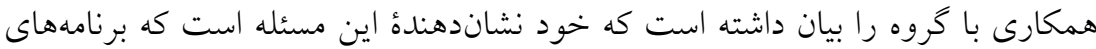

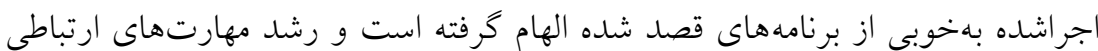

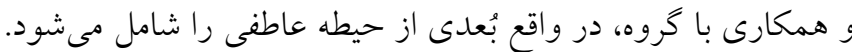

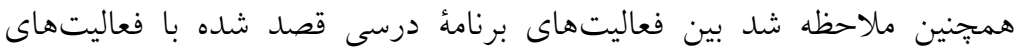

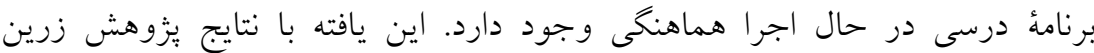

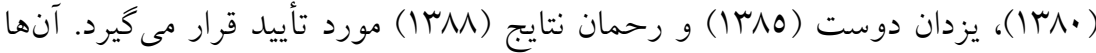




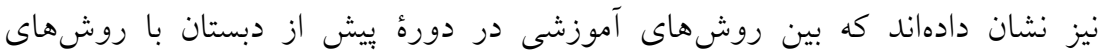

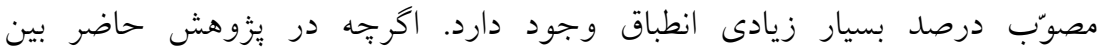

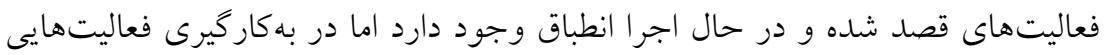

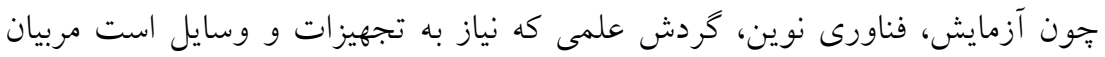

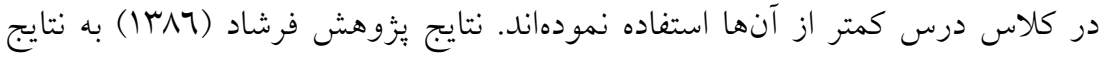

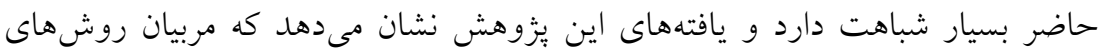

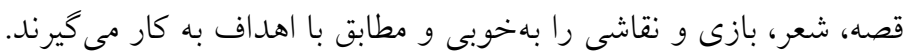

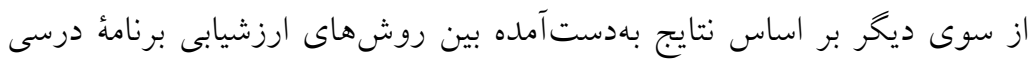

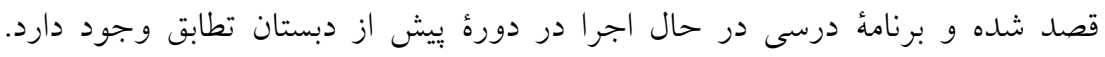

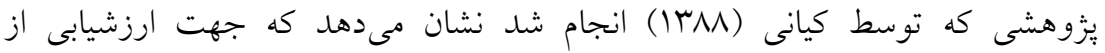

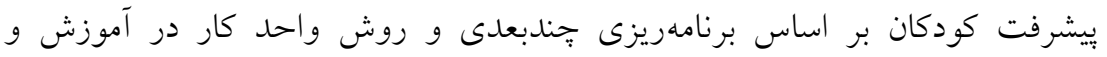

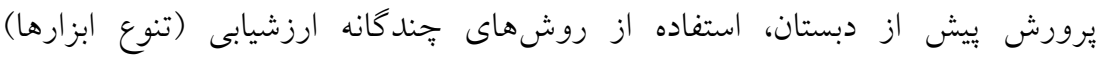

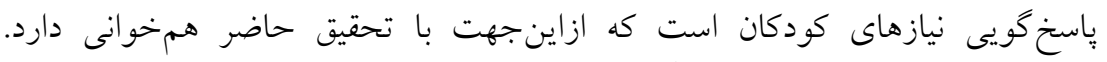

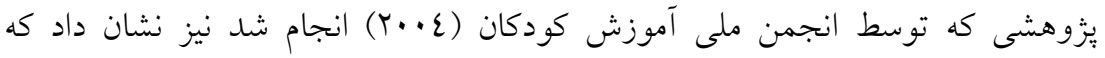

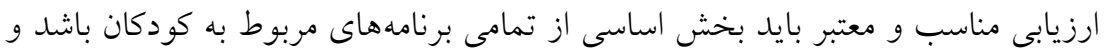

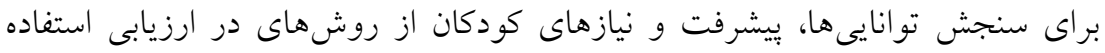

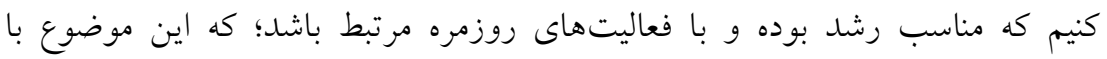

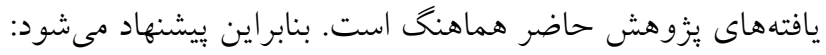

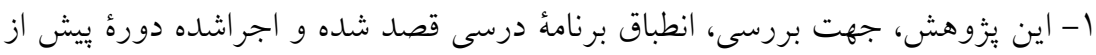

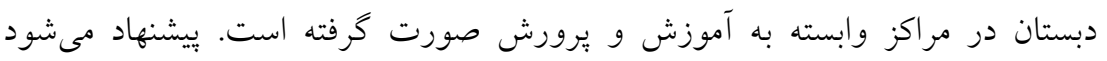

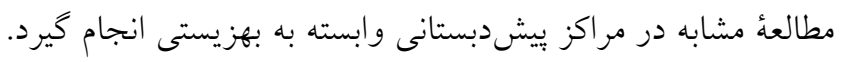

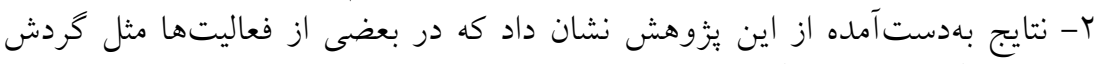

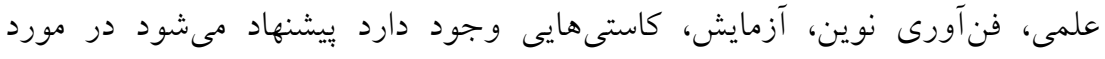

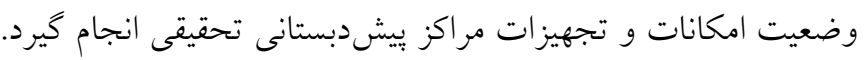

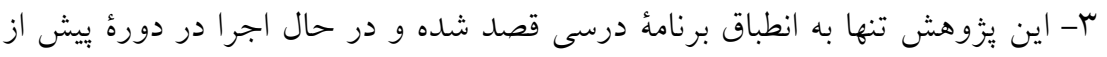

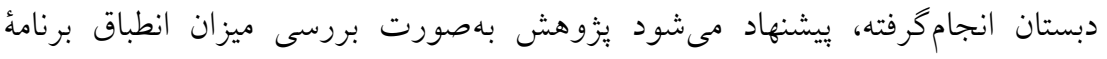

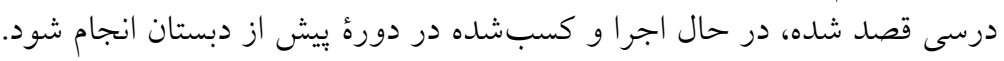




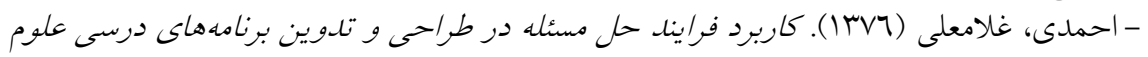

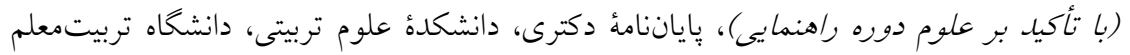
تهران.

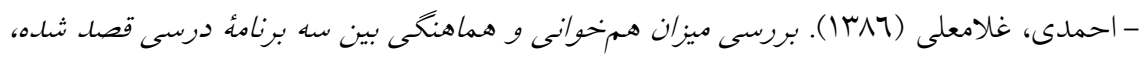

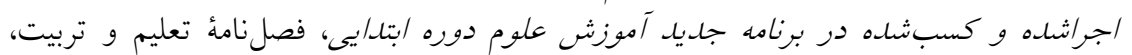

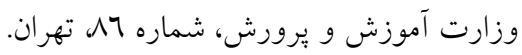

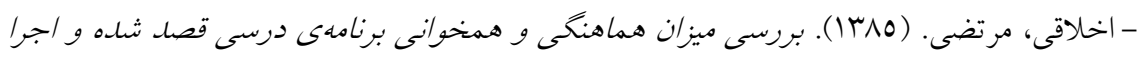

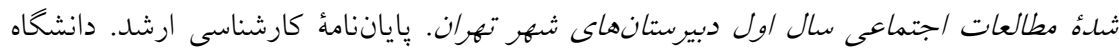
شهيد بهشتى.

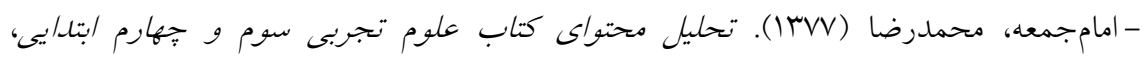

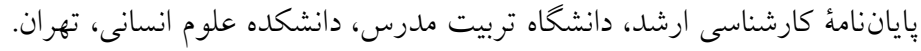

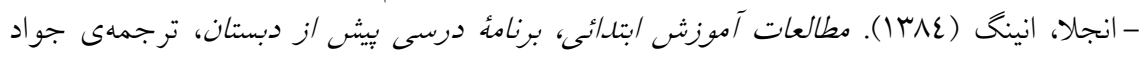

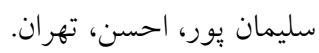

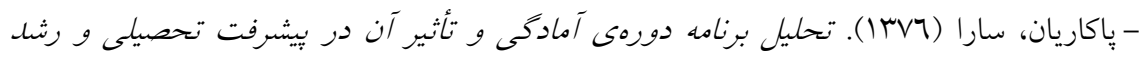

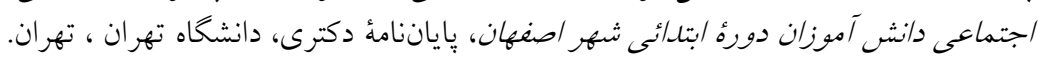

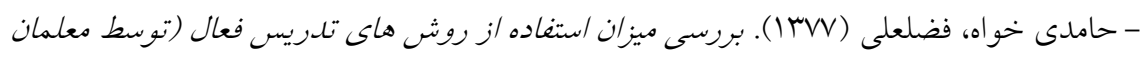

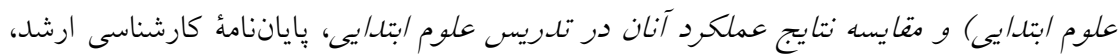
دانشگاه آزاد اسلامى اراك.

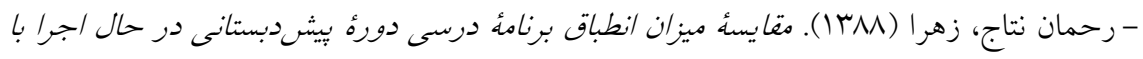

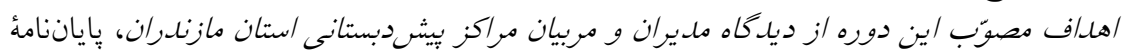

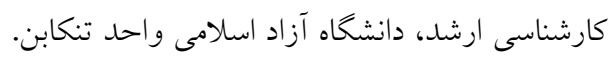

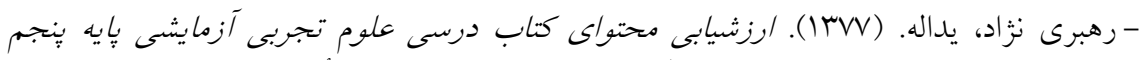

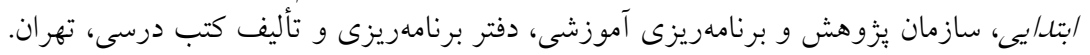

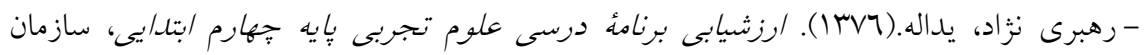

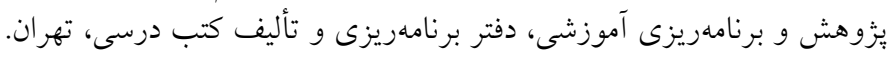

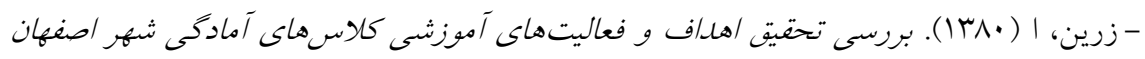

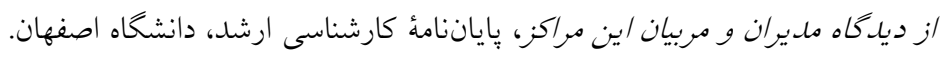

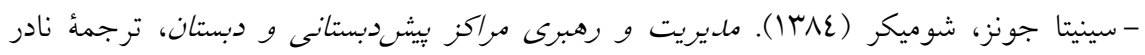

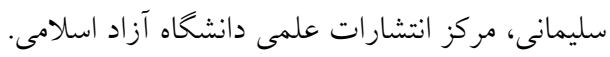

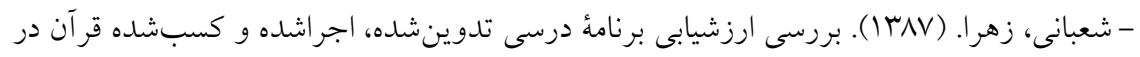

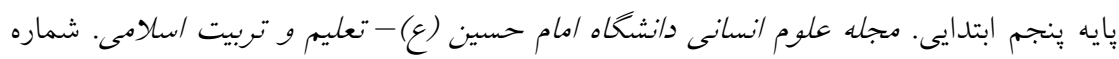




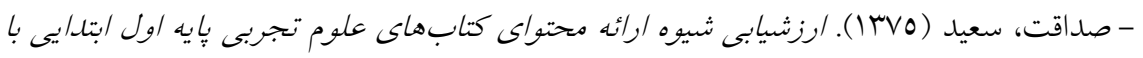

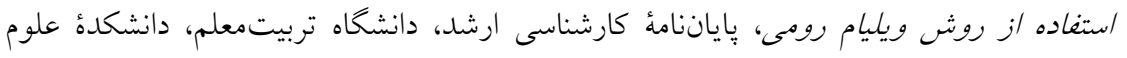
تربيتى، تهران.

- طالبزاده نوبريان، محسن (1) (1). برنامهريزى آموزش و بيرورش كودكان بيش /ز دبستان، جهاد دانشخاهى، تهران.

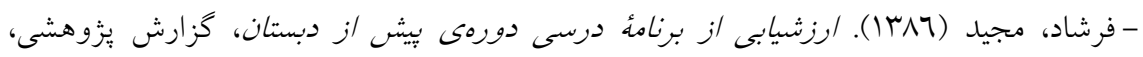

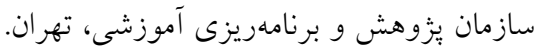

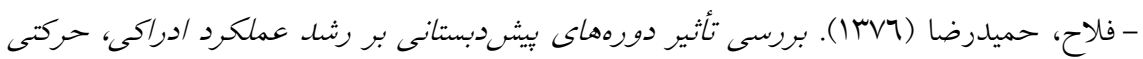

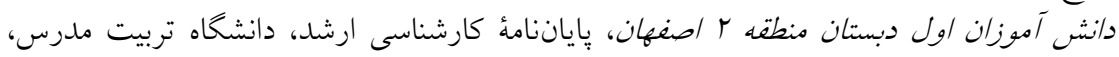
تهران.

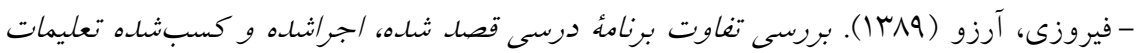

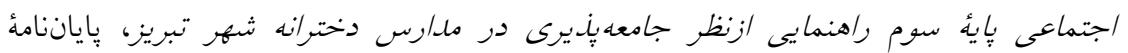

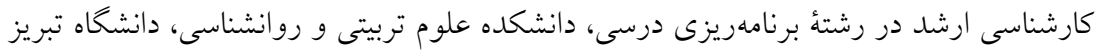

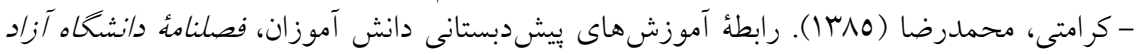

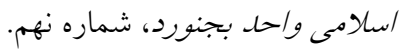

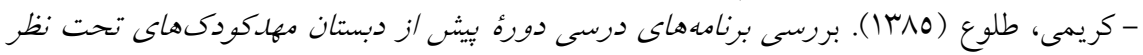

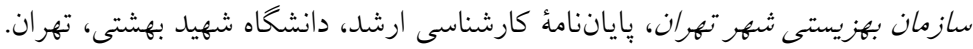

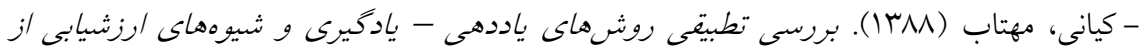

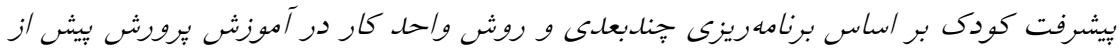

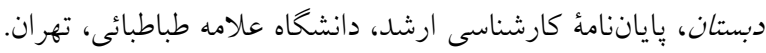

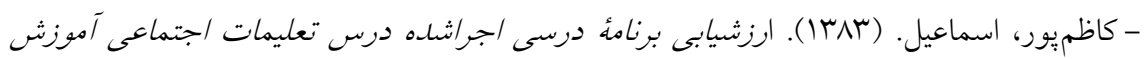

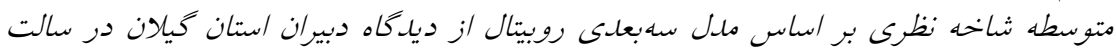

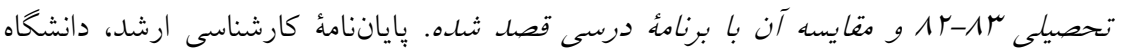
علامه طباطبايى

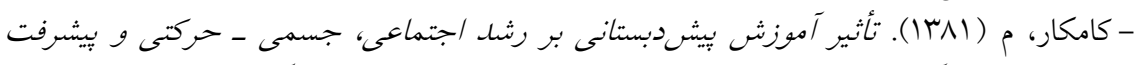

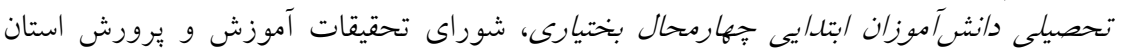

$$
\text { جهارمحال و بختيارى، شهركرد. }
$$

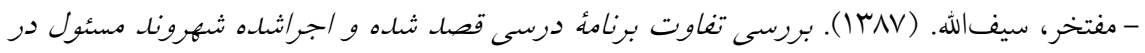

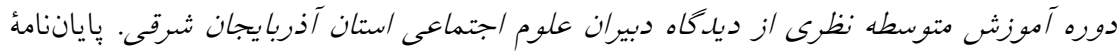

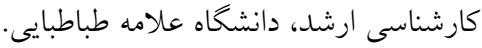

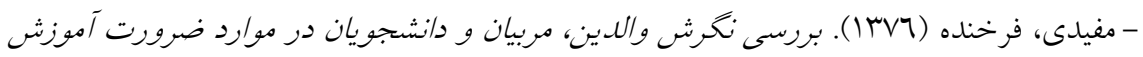

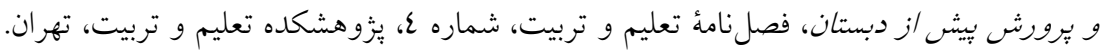




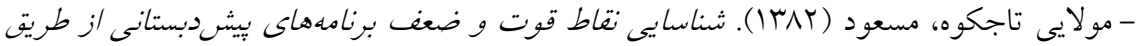

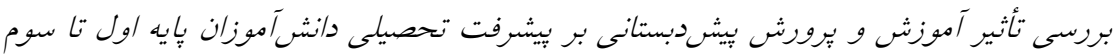

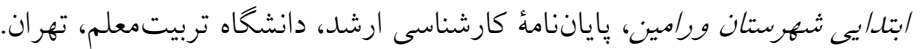

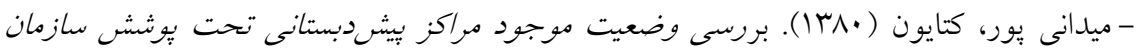

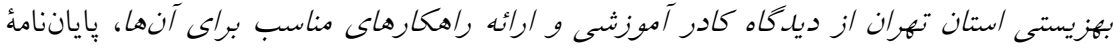

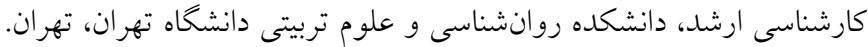

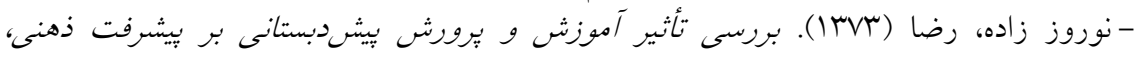

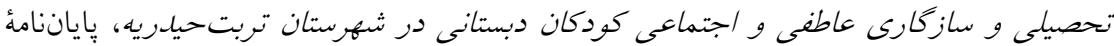

$$
\begin{aligned}
& \text { كارشناسى ارشد، دانشخاه علامه طباطبايى، تهر ان. }
\end{aligned}
$$

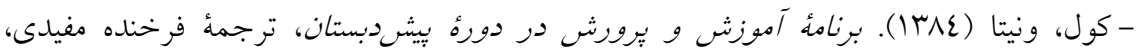

$$
\begin{aligned}
& \text { سمت، تهران. } \\
& \text { - يزدان دوست، رقيه (1/1). بروسى كيفيت مراكز بيش دبستانى برحسب محتواى آموزشى آنان }
\end{aligned}
$$

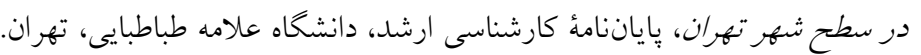

- Early Childhood Curriculum and Assessment (April 2004), Early Child Today; vol.18. Issue. 6, pp.12-13.

- Glaser, J. (2003), Pre-school and Early Education: Issues and Problems. Childhood Education, pp.13-18.

- Housden, T. and Kam, R. (2001), Full-day Kindergarten; A Summary of "The Research Carmichael". San Juan Unified School District, pp 45-48.

- Kaufman, J (1997), Evaluation Summary/Report of Preschool Program. Wisconsin: Wisconsin University pp.25-29.

- Kuamoo, Michelle (2008), An Evaluation of Quality in Early Education: the Role of Curriculum and Teacher-Child Outcomes, $\mathrm{PhD}$ theses, Caplella University pp; 114.

- Martinez Sh (2006), Summary of Research Full-day Kindergarten, Research and Evaluation Kansas Department of Education, pp 105109.

- Monica,J(2003),"A study of textbooks as the potentially implemented curriculum" Department of Mathematics Lulea niversity of technolngy. SE-971 87 Lulea, SWEDEN.

- Robitaille. D.F.et al. (1993). Curriculum Framework For Mathematics and science Canada IEA.

- Schmidt, M.H. et al (1997). Many visions, many aims: across national investigation of curricular intentions in school Mathematics (vol.1). Dordrech: Kluwer. 